\title{
As centrais sindicais e a dinâmica do emprego
}

José DARI KREIN I', Hugo Rodrigues Dias II e ANA PAULA FREGNANI COLOMBI III

\section{Introdução}

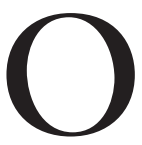
PRESENTE artigo se propõe a discutir o conteúdo da intervenção do movimento sindical (centrais sindicais) nos elementos definidores das políticas que afetam o emprego e o desemprego nos governos do PT. O enfoque não é fazer uma análise geral do sindicalismo, mas observar como se posicionou em relação às políticas econômicas adotadas e aos ensaios desenvolvimentistas empreendidos entre 2003 e 2015.

A discussão é realizada em um contexto em que há movimentos contraditórios em relação ao trabalho e às possibilidades de ação coletiva dos trabalhadores. Por um lado, com o processo de globalização, as grandes transformações no trabalho, que levam a uma reconfiguração da(s) classe(s) trabalhadora(s), e à prevalência de políticas neoliberais, de flexibilização do trabalho e de fragilização da capacidade de ação coletiva dos trabalhadores, ajudam a explicar um mundo do trabalho de crescente insegurança. O Brasil não está fora desse contexto geral, pois fez, a partir dos anos 1990, a opção de se inserir na globalização. Por outro lado, houve a vitória de um governo oriundo do movimento sindical, que apesar de ter implementado medidas contraditórias, também adotou políticas que contribuíram para elevação do emprego, para a formalização dos contratos de trabalho e para a melhora na distribuição de renda do trabalho, o que proporciona condições para desenvolver a ação coletiva. Ao mesmo tempo, o agravamento da crise atual traz novas dificuldades, como o crescimento do desemprego, que tende a proporcionar uma ação defensiva.

Considerando esse cenário, a hipótese do artigo é que o movimento sindical entre os anos 2003 e 2015, com maior participação institucional e realização de atividades unificadas, foi capaz de elaborar uma agenda, ainda que não abrangente, em defesa de um projeto com características desenvolvimentistas alicerçado no fortalecimento do mercado interno como principal indutor do crescimento econômico e promotor de emprego e renda. Entretanto, apesar de sua presença na cena política e de melhoras nos indicadores sociais e de emprego, não ocorreram mudanças estruturais que reorientassem o modelo de desenvolvimento.

O artigo está estruturado em três partes. Na primeira parte, constrói-se, a partir da literatura, um referencial teórico para afirmar a importância do sindi- 
calismo no contexto de fragilização da ação coletiva e de construção de alternativas de revitalização sindical. Nesse item, destacam-se as dimensões econômica e política da atuação sindical que, apesar de presentes na história, se recolocam na atualidade no bojo da disputa sobre os rumos do país. Se em termos teóricos enfatiza-se uma separação analítica entre essas dimensões, na estratégia metodológica utilizada no presente artigo essas esferas estão entrelaçadas.

$\mathrm{Na}$ segunda parte, apresenta-se uma periodização com a finalidade de identificar os diferentes momentos vivenciados pela dinâmica econômica e política, que orientaram e definiram a relação do governo com o movimento sindical. Os três momentos são: 1 da posse até a crise política de 2005; 2 o segundo mandato de Luiz Inácio Lula da Silva, passando pela crise de 2008/2009; e 3 o mandato de Dilma, especialmente após 2013, quando se aprofunda a crise e se revelam as crescentes dificuldades de diálogo.

$\mathrm{Na}$ terceira parte realiza-se o levantamento das formulações e ações sindicais nos períodos acima referenciados. Primeiramente, relatam-se as ações ocorridas dentro dos diferentes momentos, com destaque para as que se relacionam com a crise econômica de 2014/2015. A partir desse levantamento analisa-se a influência do movimento sindical nos rumos da política econômica, sobretudo do ponto de vista do emprego e da renda do trabalho.

\section{$O$ sindicalismo em um contexto de mudança}

Os sindicatos são um produto histórico do predomínio do assalariamento enquanto princípio organizador e estruturante das relações sociais no capitalismo. Não faltam evidências históricas de que constituiu, desde a Primavera dos Povos de 1848, um dos principais motores da crítica social nos últimos dois séculos. Esse instrumento de organização coletiva da(s) classe(s) trabalhadora(s) não se manteve inalterável. A quebra do monopólio de ofício, e a construção de um mercado de trabalho "livre", conduziu à procura de novas formas que pudessem exercer controle sobre o mercado de trabalho de forma que esta mercadoria fictícia (Polanyi, 1980) não ficasse totalmente à mercê das forças do mercado. O novo sindicalismo (Hobsbawm, 1981) britânico, com evoluções análogas em outros países do continente europeu, é produto desse mesmo movimento.

Sidney e Beatrice Webb (1894, p.1) definem sindicato como "uma associação permanente de assalariados com a finalidade de manter ou melhorar as condições do seu emprego". A sua função fundamental seria a de contraposição da vulnerabilidade do trabalhador individual na negociação do contrato de trabalho com os empregadores que, por sua vez, sofrem pressões do mercado competitivo que os impele à intensificação do trabalho e à compressão salarial. Os sindicatos eram concebidos por esses como agentes de uma revolução progressiva no sistema de relações industriais, criando mecanismos de controle social e regulação que substituíssem a autorregulação do mercado e o despotismo patronal.

Na sua análise, os primeiros sindicatos - de ofício - procuravam controlar o mercado, mediante dispositivos de restrição numérica, ou seja, definiam as 
regras de acesso à profissão, limitando o número de pessoas que a poderiam exercer. Os Webb consideravam que em longo prazo essa atitude poria em causa a regulação sindical, pois conduzia o patronato a procurar trabalho não sindicalizado. Por isso insistiram na superioridade de dispositivos de "regra comum".

A combinação inédita entre democracia e economia capitalista (Streeck, 2011 , p.5-6), que vigorou nos países capitalistas avançados no pós-Segunda Guerra, produziu mecanismos de desmercadorização institucional do trabalho, vulgo sistemas de relações industriais (Dunlop, 1958). Mas esses, longe de serem harmônicos e coesos, fruto de uma ideologia compartilhada, possuíam uma assinalável diversidade institucional. Os paradigmas pluralistas e institucionalistas aceitarão, pelo contrário, a premissa do conflito, não como uma disfunção, mas como uma realidade das sociedades capitalistas. Os estudos comparativos de relações industriais, seguindo essa perspectiva, centrar-se-ão no estudo da diversidade das instituições de regulação do trabalho e o seu impacto na variação do comportamento sindical (Clegg, 1976).

A contrarrevolução neoliberal, da qual fazem parte os processos de globalização econômica, encetou um longo processo de “destruição criativa”. De um modo geral, a ordem econômica e política construída a partir da crise de 1970 criou uma situação desfavorável ao trabalho e à ação coletiva num contexto de hegemonia do neoliberalismo e em que a globalização econômica impôs "a tirania 'racional' da mobilidade do capital sobre o trabalhador coletivo" (Burawoy, 1985, p.150), trazendo inevitáveis consequências nas modalidades de inserção econômica, formação de consciência e de ação política (Harvey, 1992, p.179).

Desse modo, os sindicatos, com ideologias e identidades específicas, inseriram-se em sistemas de relações laborais (nacionais) com trajetórias históricas singulares. Embora esses arranjos institucionais não sejam por essência permanentes, possuem uma incrustação social e histórica (Ebbinghaus; Visser, 2000), possuindo uma influência importante sobre o sindicalismo, pois é constitutiva de diferentes estruturas de oportunidades, e consequentemente de diferentes repertórios de ação sindical.

É por isso que mudanças que constituem desafios ao sindicalismo em alguns países causam pouca preocupação em outros, dada a importância que determinados temas têm para a própria constituição identitária dos sindicatos. Assim, geram-se também diferentes desafios e fontes de revitalização diversificadas (Locke; Thelen, 1995, p.338; Hyman, 2001, p.170; Hyman et al., 2014; Dias; Krein, 2015). A interação entre as estratégias do Estado e dos empregadores, instituições das relações industriais e identidades sindicais em cada contexto nacional, bem como as lutas em torno de determinadas práticas nacionais funcionam como instâncias mediadoras das pressões “externas” globalizadoras, contrariando a expectativa da convergência dos diferentes arranjos institucionais ao nível das relações laborais no sentido do modelo das economias liberais de mercado. 
Independentemente de sua filiação ideológica e projeto político e de desenvolvimento, ${ }^{1}$ o sindicalismo constitui-se em um ator econômico e político que assume posicionamentos de acordo com a transformação das circunstâncias em que opera. Se a dimensão econômica se centra mais na capacidade de obtenção de melhorias salariais e de outros benefícios, e do seu impacto na distribuição da riqueza, a dimensão política diz, sobretudo, respeito à interação com atores nos diversos níveis de governo e em três arenas de atividade de forma a aumentar a eficácia e influência no processo de elaboração de políticas públicas, seja pela participação em negociações de pactos sociais, seja pela mobilização coletiva.

Em síntese, a recuperação da discussão acima procura enfatizar a existência de especificidades que influenciam a ação do movimento sindical no tempo e no espaço. Em primeiro lugar, essa é balizada por uma trajetória histórica e institucional específica ${ }^{2}$ e por orientações políticas e ideológicas diferenciadas que moldam as suas prioridades, bem como os espaços de atuação e o repertório de ação coletiva privilegiado. Em segundo lugar, as alterações produzidas no contexto mais amplo, nacional e internacional - do qual os sindicatos são também ativos construtores -, produzem novas estruturas de oportunidades, problemas e desafios, que suscitam ajustes ou transformações mais significativas no seu perfil de atuação. Assim, embora historicamente sempre presentes, as dimensões econômica e política da ação sindical assumem diferentes combinações, de acordo com as (novas) circunstâncias em que os sindicatos desenvolvem a sua intervenção.

No Brasil dos anos 1990, ocorreu um processo de fragilização do sindicalismo, que se reflete na piora dos indicadores econômicos, no resultado desfavorável das negociações coletivas e na flexibilização das relações de trabalho. Nesse contexto desfavorável, o movimento sindical se dividiu entre os que apoiaram o ajuste conservador e as centrais críticas às opções políticas. Estas últimas buscaram desenvolver ações de resistência às políticas neoliberais, ao processo de privatização e de retiradas de direitos, apostando também na construção de uma alternativa no campo político eleitoral na esperança de reverter o quadro, que se expressou no apoio à eleição de Lula. Apesar das novas estratégias de ação, a ação sindical deste período caracteriza-se por ter ficado na defensiva (Cardoso, 2003; Krein, 2013). Nos anos 2000, abre-se um novo cenário político e econômico, que será analisado a seguir.

\section{$\mathrm{O}$ sindicalismo e os governos do PT}

A eleição de um presidente oriundo do sindicalismo gerou uma forte expectativa em relação às possibilidades de reversão dos problemas enfrentados pelo movimento sindical na década anterior, que havia sido extremamente desfavorável ao trabalho em todas as suas dimensões. Esse quadro somente se alterou depois de 2004, não obstante venha sofrendo uma nova reversão na crise atual.

De 2003 a 2015 pode-se observar a existência de três momentos distintos no que diz respeito à relação das centrais com os governos do PT. O primeiro 
vai do começo do governo Lula até a crise política de 2005. O governo assume a presidência, adotando uma política econômica ortodoxa (Barbosa; Souza, 2010), mas é favorecido pelo boom do comércio internacional e a emergência da China, que contribuíram para retomada do nível de atividade e uma crescente melhora dos indicadores econômicos e do mercado de trabalho. Na mesma perspectiva, encaminha uma agenda conservadora ao Congresso Nacional, baseada em reformas microeconômicas, tais como a lei das falências, crédito consignado, reforma da previdência, legislação diferenciada para micro e pequenos negócios etc. (Krein; Santos; Nunes, 2011). É uma agenda que gera controvérsia para o movimento sindical, pelo seu caráter flexibilizador, mas que é aprovada. Por outro lado, o governo introduz uma agenda voltada para as questões sociais e abre espaços institucionais de participação, que incluem o movimento sindical na discussão sobre os rumos do governo, tais como o Conselho de Desenvolvimento Econômico Social (CDES) e o Fórum Nacional do Trabalho (FNT).

O segundo período inicia na crise política de 2005 , quando o governo faz um esforço de se reaproximar do movimento sindical e social, incorporando uma agenda com caráter social, tais como a ampliação do Programa Bolsa Família e do aumento do salário mínimo. Ao mesmo tempo, começa a alterar a política econômica, sobretudo após a queda do ministro Palocci. No segundo mandato, os ensaios desenvolvimentistas ficam evidentes, por exemplo pela adoção do Programa de Aceleração do Crescimento, pela política do pré-sal e da Petrobras, pela geração de energia e pela estruturação de segmentos do Estado, como a ampliação das universidades. O contexto econômico internacional favorável abre espaços para dinamização do mercado interno, o que promove uma melhora substantiva dos indicadores do mercado de trabalho e do consumo. No enfrentamento da crise de 2008 , as políticas de caráter keynesiano são prevalecentes, contribuindo para que seus efeitos sobre a atividade econômica e o emprego sejam minimizados. Assim, entre 2005 e 2010, a relação entre o governo e as centrais sindicais é mais pacífica, pois todas as centrais reconhecidas ${ }^{3}$ conformam a base de sustentação do governo, com exceção das correntes mais à esquerda.

O terceiro período ocorre com Dilma Rousseff no poder, cuja eleição foi apoiada por praticamente todas as centrais. Esse apoio vai perdendo força com a constante reclamação da falta de diálogo da Presidência com as centrais e a deterioração progressiva da economia. Apesar de ter provocado uma desaceleração na economia em 2011, o governo adota políticas mais ousadas, em 2012, para reverter a queda na taxa de crescimento, por uma política de recorte mais desenvolvimentista ao reduzir a taxa de juros, incrementar o papel do BNDES, redefinir os parâmetros das concessões públicas para infraestrutura e o marco regulatório do setor elétrico, dar incentivos fiscais para o setor produtivo e desvalorizar progressivamente a moeda (Krein; Manzano, 2014). No entanto, no contexto de agravamento da crise internacional e da equivocada estratégia de 
implementação das políticas econômicas no ano anterior, os resultados não foram os esperados. Nesse cenário, abriram-se espaços para uma crescente crítica conservadora sobre os rumos da estratégia de desenvolvimento. A crise econômica se agravou a partir de finais de 2014 e combinou-se com uma crise política.

As políticas adotadas pelo governo para o enfrentamento da crise tensionaram ainda mais a sua relação com o movimento sindical, especialmente com a política de ajuste fiscal e as medidas de retirada de direitos. Processo que levou todas as centrais a adotarem uma posição crítica em relação à política econômica, embora a maioria das centrais compreenda que a defesa da democracia passe pelo respeito do voto e, portanto, do mandato de Dilma.

\section{O movimento sindical entre os anos 2003 e 2015: agenda e conflitualidade}

A descrição da atuação das centrais sindicais nas dimensões econômica e política será realizada de forma entrelaçada visto que é dessa forma que se apresentam na sociedade. Com isso buscam-se evidenciar as respostas que as centrais sindicais adotaram, do ponto de vista do discurso e da ação política, nos diferentes momentos relatados, a fim de mostrar a sua atuação na defesa de políticas voltadas ao crescimento econômico e à geração de emprego.

Apesar do apoio maciço para a eleição de Lula em 2002, a agenda e a política econômica adotada provocaram divisões no sindicalismo. Por exemplo, correntes minoritárias saíram da Central Única dos Trabalhadores (CUT) e criaram a Conlutas em 2004 (que em 2010 tornou-se CSP Conlutas - Central Sindical e Popular) e a Intersindical em 2006 (que em 2008 dividiu-se em Intersindical: Instrumento de Luta e Organização da Classe Trabalhadora e Intersindical CCT: Central da Classe Trabalhadora). As divergências principais dessas foram acerca da continuidade das políticas neoliberais e em relação à postura de parceria social desempenhada pela CUT (Galvão, 2014). A posição da CUT foi de críticas pontuais, entendendo o governo como em disputa, pois ela compunha sua coalizão de sustentação (Cardoso, 2013). Em outro extremo, a Força Sindical (FS) apresentou um discurso mais crítico à política econômica no período, a despeito de não ter realizado mobilizações contrárias à agenda em discussão no Congresso Nacional, tal como a reforma da previdência.

Essas divisões, porém, não impediram a participação ativa das centrais sindicais ${ }^{4}$ nos espaços tripartites, tais como o CDES e o FNT. O Fórum, criado com a finalidade de acordar uma reforma sindical e trabalhista, teve uma dupla dimensão. Por um lado, aumentou o dissenso entre as centrais sobre a organização sindical, provocando maiores divisões. Por outro, algumas centrais, na tentativa de assegurar alguma mudança, se aproximaram, o que contribuiu para a organização de ações conjuntas, entre as quais se destacam as marchas nacionais, a defesa de uma política de salário mínimo e da correção da tabela do imposto de renda.

No segundo período (2005-2010) prevalece uma estratégia de aproximação do governo com as principais centrais sindicais, que passam a adotar 
uma agenda propositiva e comum em defesa de um projeto de desenvolvimento econômico, chamado de Agenda dos Trabalbadores pelo Desenvolvimento, ${ }^{5}$ que busca a valorização do trabalho com distribuição de renda e em que se destacam os seguintes aspectos: a política de valorização do salário mínimo, a redução da jornada de trabalho, o fim do fator previdenciário, o estabelecimento de mecanismos contra a dispensa imotivada e a regulamentação da negociação no setor público. O ponto central da Agenda foi defender o modelo de crescimento econômico via fortalecimento do mercado interno como a estratégia capaz de gerar empregos e fortalecer os mecanismos de proteção e inclusão do trabalhador.

Além do cenário de melhora nos indicadores econômicos e do mercado de trabalho, o reconhecimento das centrais em 2008 foi um aspecto que também contribuiu para sua aproximação ao governo. Mesmo a crise internacional desse ano não foi capaz de obstar esse processo, visto que as centrais uniram-se na tentativa de propor saídas para o enfrentamento do cenário de redução do crescimento econômico e aumento do desemprego (Quadro 1).

A deflagração da crise econômica internacional promoveu a unificação de um ato em defesa do emprego, além de muitas ações no âmbito das categorias. ${ }^{6}$ Além disso, as centrais fizeram negociações com o governo federal para atenuar a crise e, entre as posições acertadas, ampliou-se o seguro-desemprego de cinco para sete meses, nos setores mais afetados pela crise. CUT e FS também se posicionaram a favor da política de desonerações tributárias a fim de estimular a retomada dos investimentos, reaquecer o ciclo de consumo e evitar um processo massivo de demissões no contexto de crise (Oliveira, 2013).

Alguns pontos não convergiram para a plataforma unificada. Por exemplo, a FS propôs uma negociação com a Fiesp de redução da jornada e salários para obstar a onda de demissões gerada pelos efeitos da crise internacional. As outras centrais rejeitaram essa alternativa, por considerar que essa negociação seria inaceitável, mesmo diante do aumento das demissões.

Depois da dissipação da crise, os atos das centrais deixaram de ser realizados até 2013, em um cenário de aparente normalidade, dado que os indicadores de emprego, renda e negociações coletivas continuavam positivos. Mesmo com a diminuição da interlocução com o governo, em alguns aspectos pontuais houve avanços na regulação do trabalho, tais como a política de valorização do salário mínimo e a PEC das domésticas (Krein; Biavaschi, 2015). Mas, também começou a aparecer uma série de manifestações de massa, tais como as rebeliões e greves nas obras do PAC e as de junho de 2013, que surpreenderam as centrais. Somente após o seu desencadeamento, as centrais procuraram desenvolver estratégias de aproximação com os manifestantes. Nas greves espontâneas de 2011, elas disputaram a representação dos trabalhadores e empreenderam uma negociação com o governo, resultando em um acordo coletivo para o setor da construção pesada. Na reação às manifestações de junho 2013 , convocaram uma paralisação nacional com a finalidade de incluir o trabalho na agenda política do país. 
Quadro 1 - Marchas e atos unificados realizados pelas centrais sindicais 20042014

\begin{tabular}{|c|c|}
\hline EVENTO E PARTICIPAÇÃO & BANDEIRAS \\
\hline $\begin{array}{l}1^{\text {a }} \text { Marcha - 2004: CUT, FS, CGT, CGTB, SDS } \\
\text { e CAT }\end{array}$ & $\begin{array}{l}\text { Recuperação de salário mínimo e correção da } \\
\text { tabela do imposto de renda. }\end{array}$ \\
\hline $\begin{array}{l}2^{a} \text { Marcha - 2005: CUT, FS, CGT, CGTB, SDS } \\
\text { e CAT }\end{array}$ & idem. \\
\hline $\begin{array}{l}3^{\mathrm{a}} \text { Marcha - 2006: FS, CGTB, CGT, SDS, CAT } \\
\text { e NCST }\end{array}$ & $\begin{array}{l}\text { Reajuste e política de valorização do salário } \\
\text { mínimo. }\end{array}$ \\
\hline $\begin{array}{l}\text { Dia Nacional de Luta - 2007: CUT, FS, CGTB, } \\
\text { UGT e NCST }\end{array}$ & $\begin{array}{l}\text { Veto presidencial à chamada Emenda } 3 \text {, que } \\
\text { restringia a atuação dos fiscais do trabalho e } \\
\text { da previdência social. }\end{array}$ \\
\hline $\begin{array}{l}4^{\circ} \text { Marcha - 2007: CUT, FS, CGTB, UGT, CTB } \\
\text { e NCST }\end{array}$ & $\begin{array}{l}\text { Redução da jornada de trabalho, mais e } \\
\text { melhores empregos, fortalecimento da } \\
\text { seguridade social, políticas públicas de } \\
\text { emprego, trabalho e renda, salário mínimo. }\end{array}$ \\
\hline $\begin{array}{l}5^{\text {a }} \text { Marcha - 2008: CUT, FS, CGTB, UGT, } \\
\text { CTB e NCST }\end{array}$ & $\begin{array}{c}\text { Desenvolvimento com Valorização do } \\
\text { Trabalho. }\end{array}$ \\
\hline $\begin{array}{l}\text { Ato Unificado - 2009: CUT, FS, CGTB, UGT, } \\
\text { CTB e NCST }\end{array}$ & $\begin{array}{l}\text { Não às demissões; ratificação da Convenção } \\
\text { 158/OIT; redução dos juros; redução da } \\
\text { jornada sem redução de salários e direitos; } \\
\text { reforma agrária; por saúde, educação e } \\
\text { moradia; em defesa dos serviços e servidores } \\
\text { públicos. }\end{array}$ \\
\hline $\begin{array}{l}\text { Jornada Nacional - 2009: CUT, FS, CGTB, } \\
\text { UGT, CTB e NCST }\end{array}$ & $\begin{array}{c}\text { Redução da jornada de trabalho; fim das } \\
\text { demissões; reforma agrária e urbana; defesa } \\
\text { de direitos sociais; ratificação das convenções } \\
151 \text { e 158/OIT; redução dos juros; defesa } \\
\text { das empresas estatais; por uma nova lei do } \\
\text { petróleo, que garanta as imensas riquezas do } \\
\text { pré-sal . }\end{array}$ \\
\hline $\begin{array}{l}6^{\text {a }} \text { Marcha - 2009: CUT, FS, CGTB, UGT, } \\
\text { CTB e NCST }\end{array}$ & $\begin{array}{l}\text { Redução da jornada para } 40 \text { horas; } \\
\text { ratificação das convenções } 151 \text { e 158/OIT; } \\
\text { PEC do trabalho escravo; Lei de valorização } \\
\text { do salário mínimo; marco regulatório para o } \\
\text { petróleo do pré-sal. }\end{array}$ \\
\hline $\begin{array}{l}7^{\text {a }} \text { Marcha - 2013: CUT, FS, CTB, UGT, } \\
\text { NCST e CGTB }\end{array}$ & $\begin{array}{l}40 \text { horas semanais; fim do fator } \\
\text { previdenciário; igualdade de oportunidades; } \\
\text { política de valorização dos aposentados; } 10 \% \\
\text { do PIB para a educação; } 10 \% \text { do orçamento } \\
\text { da União para a saúde; reforma agrária; } \\
\text { correção da tabela do IR; ratificação da } \\
\text { Convenção } 158 \text { e regulamentação da Conv. } \\
\text { 151; ampliação do investimento público. }\end{array}$ \\
\hline $\begin{array}{l}\text { Jornadas de Julho - 2013: CUT, FS, CTB, } \\
\text { UGT, NCST e CGTB }\end{array}$ & $\begin{array}{l}\text { Reforma política e cobrança em relação à } \\
\text { pauta apresentada na } 7^{\mathrm{a}} \text { marcha }\end{array}$ \\
\hline
\end{tabular}


Valorização do salário mínimo; fim do fator previdenciário; redução dos juros e $8^{\mathrm{a}}$ Marcha - 2014: CUT, FS, CTB, UGT, NCST e CGTB do superávit primário; $10 \%$ do PIB para a educação; igualdade de oportunidades; não ao PL 4330, redução da jornada; correção da tabela do IR

Fonte: Dieese (2012); Ladosky, Ramalho e Rodrigues (2014); sites das centrais.

Dado o contexto de progressiva piora nos indicadores econômicos e de crescente contestação ao governo, as divergências entre as centrais se acentuaram, como se observou na eleição de 2014. O governo Dilma optou por políticas de caráter ortodoxo no enfrentamento da crise, incluindo medidas de redução de direitos, tais como as Medidas Provisórias 665, que limita a concessão do seguro-desemprego, e 664, que restringe o acesso à pensão por morte e ao abono salarial, o que a distanciou ainda mais de parte das centrais, que foram unânimes nas críticas, apesar de adotarem diferentes tonalidades.

Para complexificar mais a situação, Eduardo Cunha, presidente da Câmara, introduz uma agenda conservadora entre as quais se destaca o Projeto de Lei n.4330/04 que regulamenta a terceirização. A sua apreciação pela Câmara gerou uma intensa reação nas redes sociais, levando as centrais a se reposicionarem no debate sobre o tema e incrementar ações coletivas de contestação ao PL. Se no início esse projeto foi objeto de bastante controvérsia, ao final, fez convergir as centrais num posicionamento crítico a ele. As mobilizações de abril e maio, como mostra o Quadro 2, foram as mais expressivas de todo o período analisado, possibilitando às centrais encontrarem novas oportunidades de se conectar com a sociedade.

O distanciamento entre CUT e FS é um fenômeno que se expressa na posição assumida em relação à natureza da crise político-econômica, apesar de a FS não possuir uma posição unificada acerca de uma proposta de impeachment da presidenta Dilma, e a respeito da regulamentação da terceirização. $\mathrm{O}$ discurso da FS destaca a dimensão econômica, considerando que o ajuste fiscal e a política monetária com altas taxas de juros favorecem o desaquecimento da economia e o aumento nas taxas de desemprego. A CUT também realiza críticas à política econômica, especialmente ao ajuste fiscal e às altas taxas de juros, mas incorpora a dimensão política, centrada na defesa da democracia, creditando à ameaça de impeachment da atual presidenta a impossibilidade de se debater um projeto de desenvolvimento com distribuição de renda.

Em 2015, as medidas de ataque aos direitos dos trabalhadores e o aumento do desemprego contribuíram para a adoção de uma postura mais reativa do sindicalismo. A CUT mudou sua posição, apesar das controvérsias internas, sobre a proposta de redução da jornada e salários para evitar as demissões, e juntamente com FS, NCST, CTB e UGT, propôs a adoção do Programa de 
Proteção do Emprego (PPE). O PPE prevê a redução da jornada de trabalho e do salário em até $30 \%$ durante o período de até um ano para empresas com dificuldades financeiras. A proposta significa uma redução de 15\% do salário e outros 15\% seriam cobertos pelo Fundo de Amparo ao Trabalhador (FAT). Em troca, o trabalhador teria o emprego assegurado por até quatro meses após o fim do acordo. É uma medida flexibilizador e defensiva.

Quadro 2 - Mobilizações das centrais sindicais em 2015

\begin{tabular}{|c|c|c|c|}
\hline Data & Evento & Participação & Pauta \\
\hline $28 / 01$ & $\begin{array}{l}\text { Dia Nacional de } \\
\text { Lutas por Emprego } \\
\text { e Direitos }\end{array}$ & $\begin{array}{l}\text { CSB,CTB,CUT, } \\
\text { FS,NCST,UGT. }\end{array}$ & $\begin{array}{l}\text { Contra o ataque e redução das } \\
\text { conquistas trabalhistas MPs } 664 \text { e } 665 \text {. }\end{array}$ \\
\hline $13 / 03$ & $\begin{array}{l}\text { Dia Nacional de } \\
\text { Lutas }\end{array}$ & $\begin{array}{l}\text { CUT,CTB,UGT, } \\
\text { NCST, CSB. }\end{array}$ & $\begin{array}{l}\text { Dia nacional de luta em defesa dos } \\
\text { direitos da classe trabalhadora, da } \\
\text { Petrobrás, da Democracia e da Reforma } \\
\text { Política. }\end{array}$ \\
\hline $15 / 04$ & $\begin{array}{l}\text { Paralisação } \\
\text { Nacional }\end{array}$ & $\begin{array}{l}\text { CUT,CTB,NCST } \\
\text { Intersindical CCT, } \\
\text { CSP Conlutas }\end{array}$ & Contra o PL 4330 \\
\hline $01 / 05$ & $1^{\circ}$ de maio & $\begin{array}{l}\text { CUT,CTB, } \\
\text { Intersindical СCT }\end{array}$ & $\begin{array}{l}\text { Em defesa dos direitos da classe } \\
\text { trabalhadora, da democracia, da } \\
\text { Petrobras e da reforma política. }\end{array}$ \\
\hline $01 / 05$ & $1^{\circ}$ de maio & FS & $\begin{array}{l}\text { Pela redução da jornada semanal } \\
\text { de trabalho; manutenção da política } \\
\text { do salário mínimo; fim do Fator } \\
\text { Previdenciário; redução da taxa } \\
\text { de juros; correção do IR na fonte e } \\
\text { revogação das MPs } 664 \text { e } 665 \text {. }\end{array}$ \\
\hline 29/05 & $\begin{array}{l}\text { Dia Nacional de } \\
\text { Manifestações e } \\
\text { Paralisações }\end{array}$ & $\begin{array}{l}\text { CUT,CTB, } \\
\text { Intersindical СCT }\end{array}$ & $\begin{array}{l}\text { Contra a Terceirização, as MPs } 664 \text { e } \\
665 \text { e o ajuste fiscal, em defesa dos } \\
\text { direitos e da democracia }\end{array}$ \\
\hline $13 / 08$ & $\begin{array}{l}\text { Grito em Defesa } \\
\text { da Indústria e do } \\
\text { Emprego }\end{array}$ & $\begin{array}{l}\text { Abimaq, UGT, } \\
\text { CGTB, FS }\end{array}$ & $\begin{array}{l}\text { Contra a recessão da economia, } \\
\text { em defesa de geração de empregos } \\
\text { e uma alerta ao processo de } \\
\text { desindustrialização. }\end{array}$ \\
\hline $20 / 08$ & $\begin{array}{l}\text { Tomar as ruas por } \\
\text { direitos, liberdade } \\
\text { e democracia! } \\
\text { Contra a direita e o } \\
\text { ajuste fiscal! }\end{array}$ & $\begin{array}{l}\text { CUT,CTB, } \\
\text { Intersindical CCT }\end{array}$ & $\begin{array}{l}\text { Em defesa dos direitos sociais, da } \\
\text { liberdade e da democracia, contra } \\
\text { a ofensiva da direita e por saídas } \\
\text { populares para a crise. }\end{array}$ \\
\hline
\end{tabular}

Fonte: Elaboração própria com base nos sites das centrais.

Já a CSP Conlutas e as Intersindicais são críticas à proposição, sob o argumento de que o PPE representa uma forma de imputar aos trabalhadores os 
custos da crise, já que esses teriam 15\% de seus salários deixados à disposição das empresas, colocando os trabalhadores e o movimento sindical à mercê de chantagem empresarial para que aceitem redução dos salários num cenário de desemprego crescente.

Nesse quadro político complicado e com o agravamento da crise econômica, as mobilizações de algumas centrais (CUT, CTB e Intersindical) em articulação com outros movimentos sociais crescem, em resposta à onda conservadora que ganha impulso. Os atos de abril, maio e agosto de 2015 são menores do que as manifestações contra o governo, mas não deixam de ser expressivas, combinando um discurso em defesa da democracia e das políticas sociais com a crítica à política econômica. É um discurso que encontra dificuldades de influenciar os rumos da política econômica, pois com sua fragilização o governo tornou-se refém dos grandes grupos econômicos, o que acentua a opção ortodoxa e praticamente inviabiliza a adoção de qualquer alternativa progressista. Isto é, a disputa nesse momento se dá em condições muito desiguais para quem defende um desenvolvimento do país baseado na distribuição de renda e na valorização do trabalho. Nesse quadro, apesar da posição das centrais sindicais, todas as medidas contra os trabalhadores foram aprovadas e com o agravamento do desemprego, a ação das centrais sindicais caracteriza-se - cada vez mais - como defensiva.

\section{Considerações finais}

Para grande parte do movimento sindical (CUT, NCST e CTB, especialmente), os governos do PT sempre estiveram em disputa, dada sua ampla coalizão de sustentação. Às centrais sindicais que apoiavam esses governos colocava-se a tarefa de, por um lado, defendê-lo das críticas da direita e da esquerda, e, por outro lado, combinar essa defesa com as posições históricas sobre o desenvolvimento do país e do trabalho.

No primeiro período (até 2005), as opções políticas do governo acentuaram as divisões internas dentro do movimento sindical, pois havia uma crítica unânime da política econômica, embora com ênfases distintas em razão da relação e participação na coalizão do poder, trazendo contradições e tensões entre o que construiu historicamente e o que defende.

No segundo período, há um processo de aproximação entre o governo e as principais centrais, em um contexto de melhora do quadro econômico e mediante a opção do governo de aproveitar a oportunidade para incrementar a questão social e do trabalho. Com a sinalização de ensaios desenvolvimentistas, as centrais apresentam uma Agenda dos Trabalhadores para o Desenvolvimento, que pode ser caracterizada como um conjunto de reivindicações. No entanto, apesar da aproximação e de um contexto mais favorável, no período não foram implementadas reformas estruturais que pudessem reorientar o modelo de desenvolvimento, mostrando que o movimento sindical não teve força para influenciar os rumos do país. No entanto, a sua participação institucional continuou muito ativa e teve espaço para discutir as medidas de enfrentamento da 
crise de 2008. Do ponto das mobilizações, as principais formas de pressão foram as marchas, mas que não tiveram grande expressão na sociedade. Assim, a facilidade de interlocução foi mais importante para influências pontuais do que a capacidade de mobilização.

No terceiro momento, especialmente após 2013, dado o não sucesso da tentativa de orientação da economia e o crescente desgaste do governo, as estratégias sindicais foram sendo mais pulverizadas, apesar de algumas atividades conjuntas. A perspectiva de defesa de um projeto de desenvolvimento conjunto se dissipa, como fica evidente no processo eleitoral de 2014 e no enfrentamento da crise de 2015. Além do agravamento da crise internacional e das opções de política econômica e de condições de governabilidade, surge uma onda conservadora muito intensa na sociedade. Nesse cenário, as disputas ficam mais explícitas, como pode ser observado, por um lado, nas manifestações contrárias ao governo e, por outro, dos movimentos sociais em defesa de um projeto progressista, da democracia e dos avanços sociais, mas com críticas centradas na política econômica. A questão é que a correlação de forças, até o momento, mostra-se desfavorável aos segmentos progressistas, apesar da resistência empreendida por parte importante do movimento sindical e social, entre outras razões pela forma desastrosa como o governo encaminhou a economia e a sua sustentação política. Enfim, hoje os espaços para uma alternativa progressista estão mais estreitos, sem o que não é possível colocar em debate a questão do desenvolvimento, tampouco pensar a quantidade e a qualidade dos empregos gerados.

\section{Notas}

I Segundo Hyman (2001), as identidades sindicais oscilaram historicamente num triângulo entre classe, sociedade e mercado. Mas mesmo o sindicalismo de mercado na prática nunca limitou a sua intervenção apenas ao campo econômico.

2 No caso específico brasileiro, a organização sindical foi constituída nos anos 1930/1940 apresentando desde sua origem uma ambivalência. Por um lado, por sua origem corporativa, o Estado estabeleceu os parâmetros de funcionamento e organização sindical, caracterizando-se como uma tutela. Por outro lado, esses mecanismos possibilitaram salvaguardas formais para o exercício da atividade sindical e da organização coletiva. Processo que possibilitou, em alguns contextos, a exacerbação dos mecanismos de controle do Estado sobre os sindicatos, mas que em outros, mais democráticos, permitiu que essa organização sindical fosse colocada a serviço da luta dos trabalhadores, a exemplo do surgimento do novo sindicalismo (Araújo, 1994; Cardoso, 2003).

3 Cf. Lei n.11.648/2008.

4 CUT; Força Sindical; CGTB - Central Geral dos Trabalhadores do Brasil; UGT União Geral dos Trabalhadores (união das centrais CGT - Confederação Geral dos Trabalhadores; SDS - Social Democracia Sindical e CAT - Central Autônoma de Trabalhadores em 2007); CTB - Central dos Trabalhadores e Trabalhadoras do Brasil; NCST - Nova Central Sindical de Trabalhadores. 
5 Disponível em: <http://library.fes.de/pdf-files/bueros/brasilien/04806.pdf>. As centrais que apoiaram a agenda: CAT; CGT; CGTB; CUT; FS; NCST e SDS.

6 Seis centrais (CUT, FS, CTB, UGT, Conlutas e NCST) realizaram o "Dia nacional de luta pelo emprego e pelo salário" e um Ato Unificado contra a crise e as demissões, reforçando que os trabalhadores não poderiam pagar a conta pela crise.

\section{Referências}

ANTUNES, R. Adeus ao trabalho? Ensaio sobre as metamorfoses e a centralidade do mundo do trabalho. São Paulo: Cortez, 1995.

ARAÚJO, A. M. C. Construindo o consentimento: corporativismo e trabalhadores no Brasil dos anos 30. 1994. 328f. Tese (Doutorado) - Instituto de Filosofia e Ciências Humanas, Universidade Estadual de Campinas. Campinas, 1994.

BARBOSA, N.; SOUZA, J. A. P. A inflexão do governo Lula: política econômica, crescimento e distribuição de renda. In: SADER, E.; GARCIA, M. A. (Org.) Brasil: entre o passado e o futuro. São Paulo: Fundação Perseu Abramo; Boitempo, 2010.

BURAWOY, M. The politics of production. London: Verso, 1985.

CARDOSO, A. M. A década neoliberal e a crise dos sindicatos no Brasil. São Paulo: Boitempo, 2003.

Para onde foram os sindicatos? In: $37^{\circ}$ ENCONTRO ANUAL DA ANPOCS.

Águas de Lindoia, 2013.

CLEGG, H. Trade Unionism under Collective Bargaining. Oxford: Blackwell, 1976.

DIAS, H.; KREIN, J. D. Sindicalismo brasileiro na encruzilhada? Fortalecimento da ação corporativa vs protagonismo social e politico. In: XVII CONGRESSO BRASILEIRO DE SOCIOLOGIA, julho, Porto Alegre, 2015.

DIEESE. A situação do trabalho no Brasil na primeira década dos anos 2000. São Paulo, 2012. Disponível em: <http://www.dieese.org.br/>.

DUNLOP, J. T. Industrial relations systems. New York: Holt, 1958.

EBBINGHAUS, B.; VISSER, J. Trade Unions in Western Europe since 1945. London: Palgrave Macmillan, 2000.

GALVÃO, A. A contribuição do debate sobre a revitalização sindical para a análise do sindicalismo brasileiro. Crítica Marxista, v.38, p.103-17, 2014.

HARVEY, D. Condição pós-moderna. São Paulo: Edições Loyola, 1992.

HOBSBAWM, E. J. Os trabalhadores: estudos sobre a historia do operariado. Rio de Janeiro; São Paulo: Paz e Terra, 1981.

HYMAN, R. Understanding European Trade Unionism - between market, class and society, London: Sage, 2001.

HYMAN, R.; GUMBRELL-McCORMICK, R.; BERNACIAK, M. Varieties of European trade unionism, varieties of challenges. In: European trade unionism: from crisis to renewal? Brussels: Etui, 2014. p.7-16.

KREIN, J. D. As relações de trabalho na era do neoliberalismo no Brasil. São Paulo: LTr, 2013. 
KREIN, J. D.; BIAVASCHI, M. B. Os movimentos contraditórios da regulação do trabalho no Brasil dos anos 2000. Revista Cuadernos del Cendes, Caracas, 2015 (no prelo).

KREIN, J. D.; MANZANO, M. Notas sobre a formalização: estudo de caso Brasil. 2014. Disponível em: <http://www.ilo.org/mexico/noticias/WCMS_245624/lang-es/index.htm>. Acesso em: 7 jul. 2014.

KREIN, J. D.; SANTOS, A. L dos; NUNES, B. T. Trabalho no governo Lula: avanços e contradições. Revista ABET, v.X, n.2, jul./dez. 2011.

LADOSKY, M. H.; RAMALHO, J. R.; RODRIGUES, I. J. A questão trabalhista e os desafios da ação sindical nos anos 2000. In: O sindicalismo na Era Lula: paradoxos, perspectivas e olhares. Belo Horizonte: Fino Traço, 2014.

LOCKE, R. M.; THELEN, K. Apples and Oranges revisited: contextualized comparisons and the study of comparative labor politics. Politics and Society, v.23, n.3, p.33767, sept. 1995.

OLIVEIRA, M. R. Resposta do Sindicato dos Metalúrgicos do ABC aos impactos iniciais da crise econômica (2008-2009). Campinas, 2013.

POLANYI, K. A grande transformação - as origens da nossa época. Rio de Janeiro: Campus, 1980.

SILVER, B. Forças do trabalho. São Paulo: Boitempo, 2005.

STREECK, W. The crises of democratic capitalism. New Left Review, n.71, p.5-29, Sept./Oct. 2011.

WEBB, S.; WEBB, B. The History of Trade Unionism. London: Longman, 1894.

RESUMO - O artigo pretende discutir as ações do movimento sindical em face das políticas que afetaram o emprego e o desemprego nos governos do PT. A referência para construção da análise é o debate sobre revitalização sindical, em que se destacam as dimensões econômica e política da ação. A analise é realizada a partir de um levantamento das ações, mobilizações e posições das centrais sindicais sobre a política econômica, classificada em três períodos distintos. A partir da análise, indica-se que, apesar de as centrais terem realizado múltiplas iniciativas, essas não se consubstanciaram em mudanças estruturais no modelo de desenvolvimento.

Palavras-Chave: Centrais sindicais, Emprego, Desemprego, Política econômica.

ABSTRACT - The article aims to discuss the actions of the trade union movement with regard to the policies that have affected employment and unemployment in Workers' Party-run governments. The framework of the analysis is the debate on trade union revitalization, particularly its economic and political dimensions. The article performs an 
inventory of union actions, mobilizations and statements on economic policy, arranged in three distinct periods. Based on this analysis, it is stated that, despite multiple initiatives by the national trade union confederations, these didn't result in structural changes to the model of development.

KErWORDS: Trade unions, Employment, Unemployment, Economic policy.

José Dari Krein é professor do Instituto de Economia da Unicamp, pesquisador do Centro de Estudos Sindicais e Economia do Trabalho (Cesit). @-darikrein@gmail.com

Hugo Rodrigues Dias é professor do Instituto de Economia da Unicamp, pesquisador do Cesit. @ - hugo.rodrigues.dias@gmail.com

Ana Paula Fregnani Colombi é doutoranda em Desenvolvimento Econômico pelo Instituto de Economia da Unicamp. Pesquisadora do Cesit. Bolsista Fapesp. @- paulinhacolombi@gmail.com

I, II e III Instituto de Economia, Universidade Estadual de Campinas, Campinas/ São Paulo, Brasil.

Recebido em 14.9.2015 e aceito em 22.9.2015. 
